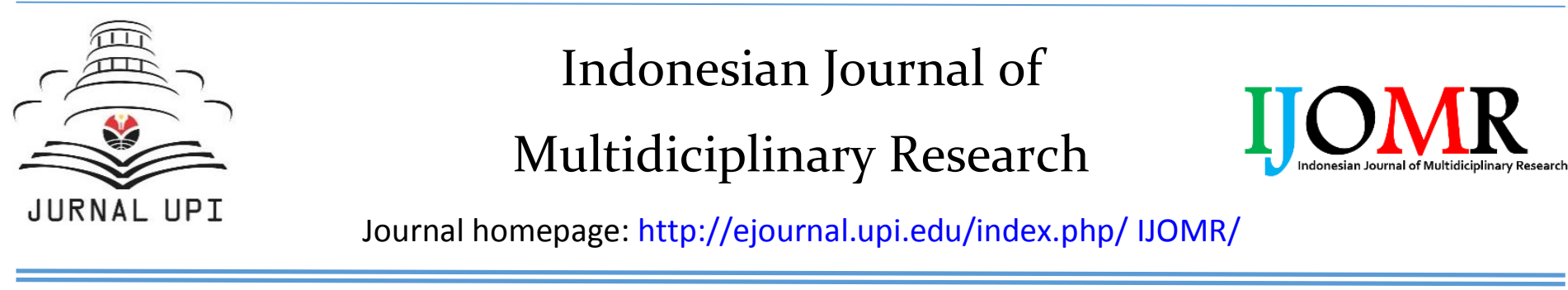

\title{
Piezoelectric Mat as Door Bell
}

Genta Yuandhana, Kania Lisdiana, Mutia Rahma Zulhaisa, Rizal Haidar Ghifari*, Syifa Nur Shadrina, Dadi Rusdiana, Tri Suwandi

Universitas Pendidikan Indonesia, Setiabudi No.229, Isola, Bandung, Indonesia Correspondence: E-mail: rizalhaidar123@gmail.com

\begin{abstract}
A B S T R A C T S
Ecological Crisis is a change in world weather which is getting warmer due to the accumulation of $\mathrm{CO}_{2}$ gas in the atmosphere. Burning rock coal which is a source of electricity generation, is a contributor to the effects of the ecological crisis in the world. This caused the world needs new energy sources, such as piezoelectric, etc. The manufacture of piezoelectric mats as house bells aims to show that there is alternative energy for power generation in order to reduce the use of coal in Indonesia. By reducing the use of coal, it will reduce the occurrence of an ecological crisis. The research method we used was an experiment with planning, design and implementation stages. The renewal of this project is to assemble and apply the piezoelectric directly to objects that require electrical energy by replacing the power source from the piezoelectric system, and implementing it for house bells. Piezoelectric mat is a mat that can generate electrical energy if the surface is pressed. This energy can be generated from the piezoelectric that is installed on the inside of the mat. Piezo mats will be installed to be stepped on by guests visiting a house. This foot step will put pressure on the mat. The more tread is obtained, the more electricity is generated. This piezo carpet will be installed in front of the house. The use of piezo mats is an effort to utilize mechanical energy in the form of pressure generated by footrests into electrical energy.
\end{abstract}

\author{
ART ICLE INFO \\ Article History: \\ Submitted/Received 30 Jan 2021 \\ First revised 10 Feb 2021 \\ Accepted 11 Feb 2021 \\ First available online 11 Feb 2021 \\ Publication date 01 Mar 2021 \\ Keyword: \\ Ecological crisis, \\ Piezoelectric. \\ Converting energy
}




\section{INTRODUCTION}

Ecological crisis is a change in world weather which is getting warmer due to the accumulation of $\mathrm{CO}_{2}$ gas in the atmosphere. Ecological is caused by burning fossil fuels, such as coal, petroleum, and natural gas, which release carbon dioxide and other gases known as greenhouse gases to the atmosphere. Burning rock coal which is a source of electricity generation, is a contributor to the effects of the ecological crisis in the world (Bamberry, 2010). This caused the world needs new energy sources, such as piezoelectric, etc.

The piezoelectric effect is where a mechanical stress applied to a material with a specific crystalline structure develops an electrical charge. Piezoelectric energy can be harvested to convert walking motion from the human body into electrical power (Howells, 2009). Piezoelectric energy harvesting has attracted wide attention from researchers especially in the last decade due to its advantages such as high power density, architectural simplicity, and scalability (Esmaeeli et al., 2019; Gonzalez-Lagunas, 2017; Fu et al., 2018; Chen et al., 2019; Bae et al., 2021). This results many experiments, including piezoelectric on roads, speed bumps, etc (Walubita et al., 2018; Chen et al., 2017). However, there is no study about piezoelectric on a mat.

The manufacture of piezoelectric mats as house bells aims to show that there is alternative energy for power generation in order to reduce the use of coal in Indonesia. By reducing the use of coal, it will reduce the occurrence of an ecological crisis.

\section{METHODS}

We use many resources and several equipment in this project as shown in Figure 1 . These were the experimental method used in this study.

1. Put the piezoelectric components on the rubber mat, using nano tape

2. Combine the capacitor with diode (rectifier) using a solder

3. Assemble a a cable circuit to piezoelectric and capacitor using a parallel spans

4. Combine with the cable and the switch, leading to the bell

5. Put the plywood above the circuit

6. Put the anti-slip gel on the plywood

7. Cover the plywood and electric components, using the cloth mat

\section{RESULTS AND DISCUSSION}

Figure 1 presented the 3D design of piezoelectric mat. The design is created using Google Sketchup, which provides the tools to design something in 3D.

The results of the experiment is that at an interval of 6 hours, this piezoelectric mat produces a different sound of bell, as listed in Table 1. Table 1 shows the relationship between the duration of applying pressure and the amount of bell sound produced. Within 6 hours the mat is kept in front of the door, the mat produces a sound that is not too loud, but after being placed for 12 hours, the mat produces a big sound. So based on this experiment the longer the piezoelectric mat is pressed, the greater the sound produced. 


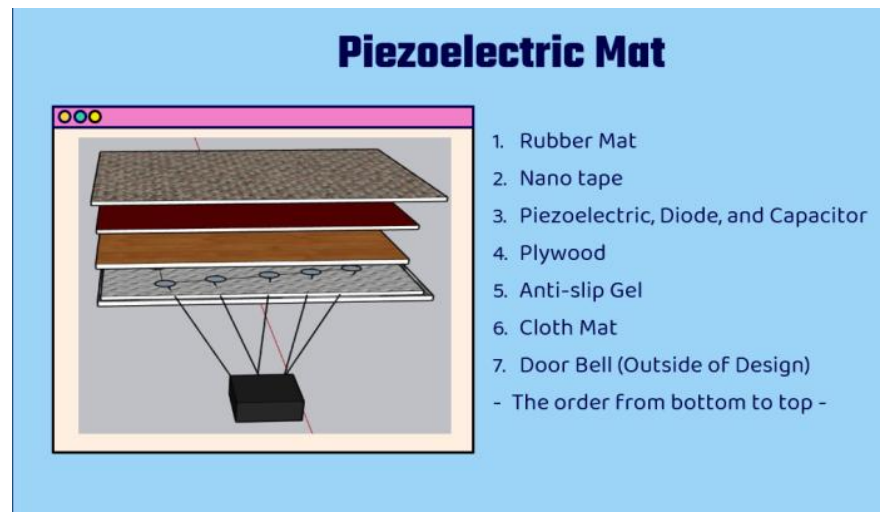

Figure 1. 3D design of piezoelectric mat.

Table 1. Experimental Result

\begin{tabular}{ll}
\hline Duration of Applying Pressure & The Magnitude of The Sound \\
\hline $\mathbf{0}$ hours & No Sound \\
6 hours & Small Sound \\
12 hours & Loud Sound \\
\hline
\end{tabular}

When the piezoelectric mat is pressed, a piezoelectric effect will occur and an AC current is supplied to the diode. Then from the diode the charge is flowed to the capacitor to store charge. The more people who use the mat, there will be a lot of pressure received by the piezoelectric. So that a lot of charge is flowed and stored in the capacitor. Then when we want to use the bell, the charge that has been collected by the capacitor will be channeled to the electric bell as needed. Because the resulting voltage is small, the piezoelectric mats are arranged in parallel.

\section{CONCLUSION}

After 6 and 12 hours of experiment, the piezoelectric mat produced the sound of a door bell. This shows the existence of alternative energy for electricity generation.

\section{ACKNOWLEDGEMENTS}

We would like to thank our Lecturers, Dadi Rusdiana and Tri Suwandi for the guidance and support for this study.

\section{AUTHORS' NOTE}

The authors declare that there is no conflict of interest regarding the publication of this article. Authors confirmed that the paper was free of plagiarism.

\section{REFERENCES}

Bae, G., Jang, D., and Jeon, S. (2021). Scalable fabrication of high-performance thin-shell oxide nanoarchitected materials via proximity-field nanopatterning. ACS Nano, 15(3), 39603970.

Bamberry, J. (2010). Blackout: coal, climate and the last energy crisis [Book Review]. Australasian Journal of Environmental Management, 17(1), 53. 
Chen, J., Qiu, Q., Han, Y., and Lau, D. (2019). Piezoelectric materials for sustainable building structures: fundamentals and applications. Renewable and Sustainable Energy Reviews, 101, 14-25.

Chen, N., Jung, H. J., Jabbar, H., Sung, T. H., and Wei, T. (2017). A piezoelectric impact-induced vibration cantilever energy harvester from speed bump with a low-power power management circuit. Sensors and Actuators A: Physical, 254, 134-144.

Esmaeeli, R., Aliniagerdroudbari, H., Hashemi, S. R., Alhadri, M., Zakri, W., Batur, C., and Farhad, S. (2019). Design, modeling, and analysis of a high performance piezoelectric energy harvester for intelligent tires. International Journal of Energy Research, 43(10), 5199-5212.

Fu, J., Hou, Y., Gao, X., Zheng, M., and Zhu, M. (2018). Highly durable piezoelectric energy harvester based on a PVDF flexible nanocomposite filled with oriented BaTi2O5 nanorods with high power density. Nano Energy, 52, 391-401.

Gonzalez-Lagunas, J. (2017). Is the piezoelectric device the new standard for facial osteotomies?. Journal of stomatology, oral and maxillofacial surgery, 118(4), 255-258.

Howells, C. A. (2009). Piezoelectric energy harvesting. Energy Conversion and Management, 50(7), 1847-1850.

Walubita, L. F., Sohoulande Djebou, D. C., Faruk, A. N., Lee, S. I., Dessouky, S., and Hu, X. (2018). Prospective of societal and environmental benefits of piezoelectric technology in road energy harvesting. Sustainability, 10(2), 383. 